\title{
A CONTRIbUiÇão do EDUCADOR JAN AMOS COMENIUS PARA A PRIMEIRA INFÂNCIA
}

\section{THE CONTRIBUTION OF JAN AMOS COMENIUS EDUCATOR FOR FIRST}

\section{CHILDHOOD}

Renata Augusta Bollis Doutoranda em Educação pela Universidade Metodista de Piracicaba. SP. Brasil. renata.bollis@hotmailcom

Resumo: O educador Jan Amos Comenius foi um dos importantes pensadores que ajudaram a modificar esta imagem de infância dirigindo-lhe um olhar dedicado. Opondo-se a práticas educacionais presentes em seu tempo, mas seguindo o pensamento metódico da ciência moderna, propôs uma Didática que tinha por objetivo central formar o bom cristão, ter fé verdadeira em Deus, praticar ações virtuosas e preparar-se para uma outra vida, estendendo esse objetivo a todos: os pobres, ricos, deficientes e mulheres. Este trabalho reconstrói as características do olhar comeniano para a primeira infância, na tentativa de observar as modificações em seu pensamento a respeito desta etapa da vida em três de suas obras. Como exemplo dessas modificações, apontamos aqui a divisão da primeira infância em quatro etapas na obra Didática Magna, e em seis etapas na Pampaedia, obra escrita cerca de vinte anos depois. Como o primeiro é o texto de maior circulação no Brasil entre os pesquisadores da História da Educação e da

Cadernos de Pós-graduação, São Paulo, v. 17, n. 1, p. 202-220, jan./jun. 2018. 
Didática, essa "fase da primavera" para Comenius tende a ser compreendida sem o aprofundamento necessário oriundo da análise das mudanças do pensamento do autor ao longo da vida. O diálogo entre estes dois textos é confrontado com uma terceira obra, intermediária, que foi recentemente traduzida para o português (2011), a Escola da Infância. Por perceber importantes diferenças entre as idades, Comenius fez propostas originais para a lide pedagógica, ao destacar a necessidade de uma atenção às crianças entre zero a seis anos, muito maior do que aquela que lhe pode dar um professor com uma grande turma de crianças. Além disso, mostrou que cada idade nesse período requer um cuidado específico que deve ser oferecido pela família para preparar adequadamente as crianças antes de mandá-las para a escola. Para analisar as três obras comeninanas citadas, este trabalho parte de uma inspiração metodológica na obra do historiador italiano Carlo Ginzburg (1989, 2001, 2006).

Palavras-Chave: Jan Amos Comenius. Primeira infância. História da Educação. Pedagogia. Obras comenianas.

Abstract: Educator Jan Amos Comenius was one of the important thinkers who helped to modify this childhood image by giving him a dedicated look. Opposing the educational practices present in his time, but following the methodical thought of modern science, proposed a didactic that had as its central objective to form the good Christian, to have true faith in God, to practice virtuous actions and to prepare for another life, extending this goal to all: the poor, the rich, the disabled and women. This work reconstructs the characteristics of the early Comic look for early childhood, in an attempt to observe the changes in his thinking about this stage of life in three of his works. As an example of these modifications, we point here the division of early childhood into four stages in the Didna Magna, and six stages in the Pampaedia, written about twenty years later. As the first is the most widely circulated text in Brazil among researchers in the History of Education and Didactics, this "spring phase" for Comenius tends to be understood without the necessary deepening coming from the analysis of the changes of the author's thought throughout the life. The dialogue between these two texts is confronted with a third, intermediate work, which was recently translated into Portuguese (2011), the School of 
Childhood. Noting the important differences between the ages, Comenius made original proposals for the pedagogical approach, emphasizing the need for attention to children between zero and six years, much greater than that can give a teacher with a large group of children. In addition, he showed that each age in this period requires specific care that the family must provide to adequately prepare children before sending them to school. To analyze the three works mentioned above, this work starts from a methodological inspiration in the work of the Italian historian Carlo Ginzburg (1989, 2001, 2006).

Keywords: Jan Amos Comenius. Early childhood. History of Education. Pedagogy. Comedy works.

\section{INTRODUÇÃo}

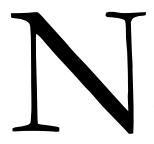

a historiografia da infância, temos, especialmente com a contribuição da obra de Philippe Ariès (1981), uma visão de que a infância, até o século XVII, não possuía as características que faziam da criança um ser com características diferentes das dos adultos. O sentimento que os adultos nutriam pelas crianças não era carregado do olhar de inocência que a modernidade legou às culturas ocidentais. Até então, elas eram tratadas como adultos em miniatura, inclusive sendo punidas como tal.

Levantando dúvidas às certezas desta corrente historiográfica, Costa (2002) aponta para um sentimento de amor parental em textos da Alta Idade Média e para a constituição de estruturas que funcionavam de forma análoga ao que entendemos como “jardins de infância” nos mosteiros. Em seus exemplos, este historiador traz à tona um sentimento de proteção à infância e ao casamento como instituições sociais importantes no período carolíngio. 
O educador Jan Amos Comenius, foi "um sonhador visionário e um utopista, na prática um não revolucionário." (CAMBI, 1999, p. 293) ou "um grande sistematizador, que chegou um pouco atrasado, quando o mundo já havia mudado mais do que ele pensava" e que estava "repleto de saudosismos medievais." (MANACORDA, 2010, p. 274). Talvez possamos entender que "Comenius não pensa em termos de transição do feudalismo para o capitalismo, embora suas soluções para a crise pressuponham sempre uma ruptura com o passado medieval”. (KULESZA, 1992, p. 102,).

Assim como teve a"[...] sua contribuição pioneira e extremamente 'atual' para a teoria educacional contemporânea. Em primeiro lugar destacam-se a percepção da identidade da criança, isso quase cem anos antes de Rousseau.” (COMENIUS, 2011a, p. 10).

Tendemos a concordar com Hilsdorf (2006, p. 129), para quem Comenius "representa exemplarmente a figura daquele intelectual atormentado que Mandrou definiu para os séculos XVI e XVII". Ainda na perspectiva de Hilsdorf (2006), esta visão "oferece uma baliza para apreciar a contribuição comeniana de agregar as ciências naturais e exatas à cultura escolar dos colégios do Seiscentos”.

Observa-se nas últimas décadas um movimento de resgate da obra deste pensador morávio, numa perspectiva que visa rememorar sua produção e compreender o alcance de suas ideias. Seus escritos e suas práticas mostram-se ainda muito desconhecidas para os dias de hoje. Em língua portuguesa, exceto por sua Didática Magna, traduções de outras obras ficaram restritas a esforços individuais na década de 1910 no Brasil e na década de 1970 em Portugal. O resgate das traduções do Labirinto do Mundo e o Paraíso do Coração e da Pampaedia, bem como a tradução da Escola da Infância, são frutos, aqui no Brasil, de trabalhos realizados nos últimos cinco anos.

Tendo ele sido um utopista ou o maior filósofo do século XVII, sendo ele um revolucionário ou não, é no espírito do sistematizador que direcionamos nosso olhar 
neste trabalho. No momento em que Comenius olha para a infância, ele procura construir uma espécie de "sequência do desenvolvimento" infantil que olha para cada idade, procurando delimitar o tipo de atenção específico que a criança precisa receber da família antes de mandá-la para a escola (COMENIUS, 2011a, p. 25).

Por perceber importantes diferenças entre as idades, ele fez propostas originais para a lide pedagógica, ao destacar a necessidade de atenção das crianças nesta idade, muito maior do que "aquela que lhe pode dar um professor que tem sob a sua guarda uma turma de crianças." (COMENIUS, 2011a, p. 75).

Justamente pelo acesso a obras comenianas escritas em diferentes períodos de sua vida, percebemos modificações no modo como ele pensou e dividiu a primeira infância. Da Didática Tcheca (publicada em 16232), passando pela Escola da Infância (publicada em 1633), e chegando à Pampaedia, (publicada em 1644), as divisões da infância passaram de quatro para seis etapas e seu conceito de educação, conforme Čapková (2009, p. 52) se amplia de uma formação do homem para uma cultura universal.

\section{O CONCEITO DE PRIMEIRA INFÂNCIA EM COMENIUS}

$\mathrm{Na}$ trilha de Ariès (1981), no novo tipo de sociedade que começou a surgir a partir do final da Idade Média, surge um novo sentimento nas famílias, em relação às crianças. A família começoua ser um lugar de proteção, e com isso iniciou a valorização desta instituição. Os filhos passaram a ser a prioridade dos pais. A principal preocupação dos pais era a saúde e educação de seus filhos.

Consequentemente a criança passou a ser um ser individual no seio familiar. Cada ser individual, neste novo modelo de sociedade que estava surgindo, é único e inigualável. Hilsdorf (2006). 
Então, a partir do século XVII, mudanças consideráveis ocorreram na sociedade. E para podermos entendê-las, precisamos abordar duas coisas, conforme nos diz Ariès (ARIÈS, 1981, p. 11):

A escola substituiu a aprendizagem como meio de educação. Isso quer dizer que a criança deixou de ser misturada aos adultos e de aprender a vida diretamente, através do contato com eles. A despeito das muitas reticências e retardamentos, a criança foi separada dos adultos e mantida a distância numa espécie de quarentena, antes de ser solta no mundo. Essa quarentena foi a escola, o colégio. Começou então um longo processo de enclausuramento das crianças (como dos loucos, dos pobres e das prostitutas) que se estenderia até nossos dias, e ao qual se dá o nome de escolarização.

A família, portanto, virou o lugar de uma afeição entre os cônjuges e entre pais e filhos. Diferentemente do que acontecia antes. Esse sentimento, afirma Ariès, aconteceu principalmente através da importância que se passou a dar à educação. Não se tratava mais apenas de educar os filhos para transmitir-lhes a herança e um ofício. "Tratava-se de um sentimento inteiramente novo: os pais se interessavam pelos estudos de seus filhos e os acompanhavam com uma solicitude habitual nos séculos XIX e XX, mas outrora desconhecida".

A família começou então a se organizar e viver em torno das crianças, que logo saíram do anonimato que falamos. Agora elas já não eram substituíveis como antes. Já não era mais possível “[...] substituí-la sem uma enorme dor, que ela não pode mais ser reproduzida muitas vezes, e que se tornou necessário limitar seu número para melhor cuidar dela”. (ARIÈS, 1981, p. 11).

Essas ideias reforçam o pensamento de Kulesza quando escreve que o livro A escola da infância, de Comenius, relata o "cotidiano da criação de filhos nas nascentes famílias burguesas do século XVII e, nesse sentido, ilustra perfeitamente bem a tese de Philippe Ariès (1986) a respeito da emergência dos sentimentos de infância e de família na modernidade”. (COMENIUS, 2011a, p. 24). 
Ele estava vivendo a mudança de pensamento da sociedade, no que diz respeito às crianças, pois a sociedade que vinha se formando, na Modernidade, já estavam preocupadas com as crianças e as tornando o centro das atenções familiares. Comenius, que inegavelmente foi um dos educadores que mais se preocupou com a educação infantil, chegou a criticar as amas de leite. Isso é um indício de que ele estava apontando para as famílias a necessidade do contato entre mãe e filho.

Entretanto, como Comenius apresenta a infância em seus escritos? A obra Didática Magna, que é a mais conhecida de Comenius, ao tratar da Primeira Infância, não faz uma divisão dessa fase da vida de modo mais detalhado como o fez na obra Pampaedia.

Comenius redigiu a Pampaedia (Educação Universal) que é a quarta das sete partes que constituem a obra intitulada Deliberação Universal Acerca da Reforma das Coisas Humanas (De Rerum Humanarum Emendatione Consultatio Catholica), por volta de 1644. Vale ressaltar que nessa época ele também já era um homem mais amadurecido com suas ideias e pelos dissabores da vida. Talvez por isso seja a sua obra mais completa. Comenius, ao escrever essa obra, estava em uma fase mais madura por isso ampliou em um conceito universal de educação e perfeição de todos os homens a ser adquirido durante toda a vida, do período pré-natal à morte. (GASPARIN, 1994, p. 103).

Em Pampaedia, que é a educação universal de todo o gênero humano, pretendese, que todos sejam educados em todas as coisas e totalmente. É dedicado à arte de implantar a sabedoria nas mentes, nas línguas, nos corações e nas mãos de todos os homens.

Comenius acreditava que, apesar desta vida ser apenas uma preparação para a outra vida, o homem foi criado para a felicidade neste mundo, ou seja, o homem está 
neste mundo para ser feliz, pois considerava o ser humano como um inestimável tesouro divino, e em especial as crianças. Não há nada mais comeniano para explicar isso, do que a passagem abaixo:

Com efeito, o objetivo desta vida é preparar-se para a eternidade, e se isso se não faz na vida, a vida perde-se. E uma vez que a eternidade se chega por meio da morte, os homens devem, portanto, preparar-se para afrontar bem a morte. E porque se não chega a uma boa morte a não ser através de uma vida boa, devem preparar-se, já desde o início da vida, para uma vida boa. E porque se não chega a uma vida boa a não ser através de uma boa educação, a juventude deve, portanto, desde os primeiros anos, serem habituada a fazer bem tudo aquilo que faz. (COMENIUS, 2014, p. 150).

A Escola da Infância a qual Comenius se refere, que ele também a chama de A Escola da Infância: O Regaço materno. Podemos concluir, que essa escola, tem um valor especial para Comenius, tanto que ele escreveu um livro somente dedicado a esta etapa da vida criança. É o livro que foi traduzido do tcheco para o português, por $W_{o-}$ jciech Kulesza, publicado em 2011 pela Editora Unesp, com o título $A$ escola da infância.

A escola da infância, na Pampaedia, foi composta para atender a educação das crianças, desde a concepção até os seis anos de idade. Comenius foi mais abrangente que nossa atual educação infantil, mas, não menos sagaz e sensível, além de "envolver uma concepção abrangente de todo o processo educativo, em todas as suas dimensões e fases, coerentemente com o próprio espírito de sua contribuição teórica". (COMENIUS, 2011a, p. 10).

Comenius foi um dos educadores do século XVII que mais se preocupou com as crianças, na primeira idade, tanto que Kulesza diz que o seu livro a Escola da Infância é um tributo a mulher como mãe. Para Comenius, cuidar da infância é um ato educacional, preocupação presente nos discursos sobre educação infantil dos dias de hoje.

De qualquer forma, isso ressalta o que dissemos acima, que o livro a Escola da infância, mostra a história da época, que relata o dia a dia da criação das crianças nas 
famílias burguesas que surgiam no século XVII (COMENIUS, 2011a) enfatizando a idéia de Ariès (1981) a respeito da emergência dos sentimentos de infância e de família na modernidade.

Dentro deste contexto que estamos analisando importante mostrar o pensamento de Comenius sobre a primeira infância na Didática Magna:

Os ramos principais de uma árvore, por mais numerosos que sejam, despontam do tronco logo nos primeiros anos; depois disso apenas crescem. Do mesmo modo tudo aquilo em que o homem deve ser instruído, e que lhe será útil durante toda a vida, deverá ser semeado e plantado desde a escola materna. (COMENIUS, 2011b, p. 325).

A infância é a primavera da vida. É nessa etapa que florescem os sentidos, e então o que aprendemos aí levaremos para o resto de nossas vidas. Se aprendermos a ser honestos, piedosos, caridosos seremos para sempre.

Comenius, como um homem religioso que sempre foi, pois a congregação Irmãos Morávios sempre esteve presente intrinsecamente no "eu”, tinha também a justificativa religiosa para a preocupação e cuidado com as crianças. Diz o autor (COMENIUS, 2011b, p. 28) que "se alguém quiser entender por que Deus considera e exalta tanto as crianças, não encontrará melhor motivo que o de, na criança, ser tudo mais simples e mais apto a receber o remédio que a misericórdia divina oferece às enfermiças condições humanas."

O fato de Comenius vincular sua didática a concepções religiosas não tira o mérito de sua proposta educacional. Temos que ver além "dessas brumas", porque

[...] as crianças são os bens mais puros e queridos possuídos por Cristo, que veio a todos salvar, exceto àqueles possuídos por Cristo, que veio a todos salvar, exceto àqueles obnubilados por sua própria incredulidade e impenitência. Como as crianças ainda não estão separadas de Cristo, mantêm plenamente seu direito à salvação e delas é o reino dos céus. (COMENIUS, 2011b, p. 3). 
Portanto não podemos tirar o mérito de Comenius, em relação à sua preocupação e contribuição com a infância, pelo fato de ter conceitos e justificativas religiosas, pois pode até ser que suas contribuições não sejam pioneiras, mas sem dúvidas são atuais, principalmente no que diz à percepção da identidade da criança.

\section{AS DIVISÕES DA PRIMEIRA INFÂNCIA EM DIDÁTICA MAGNA, A ESCOLA DA INFÂN- CIA E PAMPAEDIA}

No livro Didática Magna, Comenius apenas tratou da escola materna, ou primeira infância, como método de estudo, ou seja, dizendo o que deve ou não se deve estudar nessa fase. Diferentemente do que fez depois em Pampaedia.

Nesta obra Comenius não aparece divisões em classes da primeira infância, e sim em quatro momentos. Começa dizendo que "[...] na escola materna devem ser exercitados, sobretudo os sentidos externos, para que os alunos se habituem a usá-los de maneira correta para o conhecimento dos objetos". (COMENIUS, 2011b, p. 321).

Segue com sua explicação da primeira infância, na qual

[...]tudo aquilo em que o homem deve ser instruído, e que lhe será útil durante toda a vida, deverá ser semeado e plantado desde a escola materna. De que modo isso é possível ficará claro se percorremos todos os gêneros do saber: mostrá-lo-ei com poucas palavras, lembrando todos os vários gêneros de saber em vinte parágrafos.(COMENIUS, 2011b, p. 325).

Os quatro momentos, para o autor, nesta obra, inicia-se com a fase dos primeiros passos. Segue, então para a linguagem (palavras e gestos), a fase dos bons costumes e da piedade e termina apresentando a escola coletiva, para a qual "seria muito útil [...] um livro ilustrado com figuras, que seria entregue às crianças”. (COMENIUS, 2011b, p. 332). 
Ele trata destes quatro momentos e do método de ensino, em vinte parágrafos, descrevendo como deve ser a educação das crianças, os conteúdos a serem ensinados e o modo de ensiná-los. Diferentemente do que fará na Pampaedia, ele não faz menção à "classe puerperal", até a idade de um mês e meio (quarentena) e a "classe do aleitamento materno".

$\mathrm{Na}$ Escola da Infância, ele também não esboça divisões, mas avança um pouco mais que na Didática Magna, isto é, ele fala, além dos quatro momentos da Didática Magna, ele, apesar de não utilizar a palavra "classe" traz vários conselhos e instruções sobre os cuidados com o recém-nascido e o modo como se deve amamentar o bebê. Por exemplo, ela já levantava uma crítica que Rousseau faria em seu Emílio, que o recém-nascido não deveria ficar preso, sem movimentos, enfaixado, mas sim solto e livre para se movimentar.

Em relação ao período puerperal, o avanço se deu, talvez, devido à grande mortalidade infantil, em sua época, por falta de higiene dos pais para com elas. Tanto que Comenius escreve: "Depois de ter vindo à luz, convenientemente lavada e limpa, a criança será vestida de maneira delicada, com roupas suaves e quentes, e adequadamente alimentada pelos pais". (COMENIUS, 2011a, p. 26).

No que diz respeito ao aleitamento materno, Comenius não ficou omisso nesse sentido e também deu seus ensinamentos:

Nesse momento é importante que a mãe seja ela mesma a nutriente, não afaste de si sua própria carne, continuando a dar alimento a quem começou a alimentar em suas entranhas. Mas ó dor! Quão danoso e repreensível é o costume oposto daquelas mães (da nobreza mais respeitável) que, enfastiadas de cuidar de sua própria descendência, permitem que ela seja mantida por fêmeas estranhas. Esse fato horroroso deve ser denunciado onde acontecer para que se adotem os procedimentos prudentes que a própria necessidade impõe. Pois quanto menos esse costume se radicar, menos se disseminará e menos necessidade haverá de suprimi-lo, sobretudo onde planejamos estabelecer a boa ordem a partir de seus fundamentos. Digo então que a cruel separação da criança de sua mãe para dá-la a uma ama de leite

Cadernos de Pós-graduação, São Paulo, v. 17, n. 1, p. 202-220, jan./jun. 2018. 
(a não ser nos casos inevitáveis, como quando a mãe não é capaz de amamentar) é primeiro, contra Deus e a natureza, segundo, prejudicial aos filhos, terceiro, perniciosa para a própria mãe, quarto indigna e altamente reprovável. (COMENIUS, 2011a, p. 26, grifo do autor).

Para ele, se Deus deu esse leite para a mulher, então ela tem a obrigação (divina) de dar esse leite ao seu filho. Como a criança já está acostumada desde o útero a se alimentar com o sangue materno, deve continuar recebendo o leite quando bebê. $\mathrm{Na}$ verdade, podemos dizer que ele estava fazendo uma crítica a muitas famílias ricas da época, pois quem tinha amas de leite eram os abastados e não os pobres.

$\mathrm{Na}$ Escola da Infância, o autor basicamente repete, com alguns detalhes adicionais, os quatro momentos da infância presentes no Didática Magna. Para o autor, por exemplo, desde a gestação, a mãe e o pai devem ser piedosos para que o filho desde o ventre materno aprenda isso.

Em Pampaedia, ele dividiu a primeira infância em seis classes, esboçando um esquema de como é, para ele, a divisão da primeira infância. (COMENIUS, 2014, p. 173).

$$
\begin{aligned}
& \text { I - A classe puerperal, até a idade de um mês e meio; } \\
& \text { II - A classe do aleitamento, até a idade de um ano e meio; } \\
& \text { III - A classe do balbuceio e dos primeiros passos; } \\
& \text { IV - A classe da linguagem e da percepção sensível; } \\
& \text { V - A classe dos bons costumes e da piedade; } \\
& \text { VI - A primeira escola coletiva, ou seja, a classe das primeiras letras. }
\end{aligned}
$$

Portanto, em Pampaedia, sua obra mais madura e abrangente, ele explora mais essa divisão e classificação do que nas outras obras. Vejamos alguns exemplos de como o autor trata de cada uma delas. A classe puerperal apresenta instruções semelhantes àquelas presentes na Escola da Infância. Para o autor, logo que acabam de vir ao mundo, as criancinhas devem ser consagradas aos serviços de Cristo, por meio de orações, batismo, boa educação. 
Igualmente, repete na classe do aleitamento, sua leitura de que a prole deve ser amamentada, com o leite da mãe, pois é o leite da graça de Deus, e para que forme as suas raízes, já que é o leite materno. E para as que não podem amamentar, ou as mais nobre, que talvez precisem de amas de leite, que arruem uma ama que seja sã, honesta e piedosa.

$\mathrm{Na}$ classe do balbuceio e dos primeiros passos, deve-se ensinar para as crianças as palavras com auxílio das cosias, para que possa verificar o que Salomão falou: "a sabedoria abre a boca dos mudos e torna eloqüentes as línguas das crianças (Sabedoria, 10, 21)". (COMENIUS, 2014, p. 175). Assim, os pais ou as amas vão ensinando através dos nomes das coisas, com as palavras mais simples e pelas partes maiores.

Comenius diz que a criança deve ser exercitada no corpo e no espírito. “[...] Devem ser exercitadas nos movimentos, fadigas e no frio" (COMENIUS, 2014, pp. 175-176), como os persas ensinavam seus filhos, durante os seis primeiros anos. Primeiramente as mãesnão devem ter preguiça. Desde que ficara grávida, deve mudar seus pensamentos.

Depois que o filho nascer, os pais devem deixar as crianças se movimentarem e sempre fazer a criança feliz. Portanto, as crianças não devem ser educadas com moleza, mas, seguindo os exemplos dos espartanos: com agilidade, para o trabalho e para suportar as adversidades, ou ainda habituadas ao trabalho, à prudência (adquire esta ao errar e depois tomar consciência dos seus erros) e a procurar por toda a parte o uso das coisas. (COMENIUS, 2014, p. 176).

$\mathrm{Na}$ classe da percepção sensível, as crianças desta ainda não possuem nenhum conceito, nem bom nem mau, devendo os conceitos serem introduzidos através dos sentidos. "Ora, nada está na inteligência que primeiro não tenha estado nos sentidos". (COMENIUS, 2014, p. 177). Comenius enfatiza que as primeiras impressões sempre apegam firmemente. "Portanto, porque o governo de toda a vida depende dos sentidos, 
como foi justamente observado pelos filósofos, colocados no recto caminho, os sentidos farão com que tudo proceda devidamente”.(COMENIUS, 2014, p. 178).

A linguagem começa sempre como focoo tato e a vista. Será de suma importância, portanto, as crianças terem por toda a sua vida, os sentidos voltados para as coisas, pois assim vai acostumar-se a dar seu consentimento apenas à verdade e a basear-se em seu próprio juízo. (COMENIUS, 2014, p. 178-179),

Tudo isto é fácil de conseguir, pois, como diz Sêneca, na Epístola 109: "Muito facilmente os espíritos tenros são impelidos para o amor do honesto e do bem. A verdade apodera-se dos espíritos ainda mais dóceis, ou levemente corrompidos, se encontrarem um advogado idôneo". Com o que está de acordo a voz de Deus (Isaías, 28, 29). (COMENIUS, 2014, p. 179).

$\mathrm{Na}$ classe dos bons costumes e da piedade, ele diz que é proibido, nessa etapa da vida infantil levar uma criança a ter ira, raiva, ódio, pois se ela se habituar a isso, vai ser difícil tirar este hábito. Como nossas raízes começam na primeira infância, a criança seguirá com esses costumes até a fase adulta.

São três os processos de ensinar os bons costumes para crianças. O primeiro são os exemplos. Ensinar é guiar. E ensina-se através do exemplo, ou seja, o educador tem que ser o exemplo para as crianças, caso contrário não vai funcionar. "Portanto aqui, é necessária, antes de tudo, a proteção dos sentidos, como recordamos pouco atrás, e este é o grande segredo da educação.” (COMENIUS, 2014, p. 180).

O segundo é a instrução. É necessário que a instrução seja clara, nítida e feita, de preferência comparábolas. "nas crianças, logo que, qualquer coisa começa a manifestar-se naturalmente, deve começar a ser dirigida e a ser educada, para evitar que, abandona a si mesma, se desenvolva de modo nocivo". (COMENIUS, 2014, p. 180). O terceiro é a disciplina. Não se trata de bater fisicamente nos filhos, e sim, em uma 
atenção para que eles façam o certo, sendo prudentes, orientando-os a fazer o bem. (COMENIUS, 2014, p. 181).

Por fim, o autor apresenta a classe coletiva e prática do regaço materno, a última classe ante de enviar a criança para a escola pública. Assim define o autor essa classe:

É, em certo sentido, uma escola semi-pública, onde as crianças se habituam a convier, a brincar, a cantar, a contar, a cultivar os bons costumes e a piedade, e a exercitar os sentidos e a memória (antes de começarem a aprender a ler e a escrever) sob a direção de Senhoras honestas, em casa das quais se juntam as criancinhas das redondezas (entre os 4 e 6 anos, mais ou menos), a expensas daqueles que querem que os seus filhos sejam formados suavemente e preparados para a escola pública." (COMENIUS, 2014, p. 184).

Isso seria o jardim de infância. Para Comenius, primeiramente os pais tem que preparar os filhos adequadamente para poder frequentar a escola pública. Depois de ensinar corretamente, com exemplo, disciplina, prudência os filhos estariam preparados.

A questão da presença da criança na família e a necessidade de uma educação consciente e metódica da parte dos pais até os seis anos de idade é um marco da proposta comeniana para a primeira infância. Já, na Escola da Infância, Comenius afirmava:

Não aconselho que os meninos sejam apartados do regaço materno antes dos 6 anos de idade [...]. Primeiro, a criança pequena requer muito mais atenção do que aquela que lhe pode dar um professor que tem sob sua guarda uma turma de crianças. Portanto é melhor acalentá-la no regaço materno. Segundo, é aconselhável que o cérebro esteja bem consolidado antes da criança começar a exercer atividades e somente por volta do quinto ou sexto ano o crânio se fecha completamente, enrijecendo o cérebro. [...] Por outro lado, não é razoável manter as crianças em casa depois dos 6 anos [...]. (COMENIUS, 2011a, p. 75, grifo do autor). 


\section{CONSIDERAÇÕES FINAIS}

Vimos até aqui, que Comenius salienta que as crianças devem aprender pelos sentidos. Ele teve essa percepção, pois à época em que vivia, viu que "a passagem da criança pela família e pela sociedade era muito breve e muito insignificante para que tivesse tempo ou razão de forçar a memória e tocar a sensibilidade”. (ARIÉS, 1981, p. 10).

Comenius, que não estava sozinho, mas foi um dos educadores que se preocupou o modo como as crianças eram tratadas e propôs soluções, através de seus livros, na igreja que freqüentava, já que estava diante dessa situação com a qual não concordava. O educador tcheco afirma na obra Pampaedia (COMENIUS, 2014, p. 163), que "toda a esperança de uma reforma universal das coisas depende da primeira educação". Isso porque, para esse educador é na infância que devemosnos esforçar ao máximo para com os pequenos. É na infância que devemos plantar as sementes. Isto é aparece desde a Didática Magna (COMENIUS, 2011b, p. 325):

Os ramos principais de uma árvore, por mais numerosos que sejam, despontam do tronco logo nos primeiros anos; depois disso, apenas crescem. Do mesmo modo, tudo aquilo em que o homem deve ser instruído, e que lhe será útil durante toda a vida, deverá ser semeado e plantado desde a escola materna". "Portanto, os homens devem ser instruídos desde cedo, não apenas por causa de si mesmos, mas também por causa dos outros, pois, (como diz Cícero com razão), o fundamento de toda a República é a recta educação da juventude.

Para Comenius (2014, p.165), o principal responsável pela educação dos filhos sãoaos pais, cabendo a eles a primeira educação antes de mandá-los para a escola, aos sete anos de idade. E não devem esquecer que a infância é a primavera da vida, não podendo descuidar dessa fase dos filhos, pois é o momento de preparar o espírito das crianças. 
A preocupação e o trabalho com a educação infantil, pudemos notar em todas as três obras analisadas aqui. Pudemos observar, também, a evolução e amadurecimento de Comenius nestas obras. Ele que começou com Didática Tcheca, depois traduzindo para o latim, e produzindo a Didática Magna, na qual a primeira infância tinha quatro momentos e uma preocupação mais geral com a questão do método. Depois a descreveu em seis fases, e mostrando como se educa em cada momento. Anos depois, ele escreveu Pampaedia, no qual sistematizou as seis classes da primeira infância, detalhando e aprofundando cada uma delas.

Kulesza (1992, p. 153), aponta para as características desse aprofundamento, que não ocorreu apenas em relação à primeira infância. Para ele,

[...] a evolução do seu pensamento em direção a uma pansofia pouco a pouco deixa para um segundo plano suas preocupações estritamente pedagógicas, para se voltar integralmente para seu ideal reformista no sentido da rerum humanarum emendatione. Naturalmente, esta orientação se reflete na sua visão $[. .$.$] .$

Vemos então que um maior detalhamento e ênfase da primeira infância na Pampaedia, em relação à Didática Magna, veio da evolução e amadurecimento de Comenius que refletiu em suas obras. E que, segundo Kulesza (1992) é uma ordem natural no processo de aquisição do nosso conhecimento. "O gênio de Comenius consiste em ter compreendido que a Educação é um dos aspectos dos mecanismos formadores da natureza, havendo assim integrado o processo educativo a um sistema onde este processo constitui justamente o eixo essencial". (KULESZA, 1992, p. 124).

Isso porque Comenius escreveu o livro Escola da infância, quando suas filhas, do seu segundo casamento, nasceram. Elas "conviveram com ele durante a redação de seu manual". (COMENIUS, 2011a, p. 10). Não é à toa que Piaget se remete a Comenius como um precursor. Kulesza (1992, p. 124) menciona que: 
Há portanto, uma ordem natural no processo de aquisição de nosso conhecimento e, assim, a aprendizagem deve seguir o caminho da natureza. Em nossos tempos, é Piaget quem destaca em Comenius o mesmo princípio, considerando-o, inclusive, precursor de sua epistemologia genética:

Comenius mostrou como educar as crianças de zero a seis anos de idade. Ele foi um dos primeiros educadores a preocupar com a identidade da criança. Ou seja, hoje a criança é o centro da atenção da família, e como vimos, nem sempre foi assim. Se hoje esse é o pensamento da sociedade, devemos, não só a Comenius, obviamente, mas a todos os pensadores que um dia se preocuparam com as crianças no passado.

\section{REFERÊNCIAS}

ARANHA, M. L. de A. Filosofia da educação. 2. ed. São Paulo: Editora Moderna, 1996.

ARIÈS, P. História social da criança e da família. 2. ed. Rio de Janeiro: LTC, 1981.

CAMBI, F. História da pedagogia. São Paulo: Editora Unesp, 1999.

COMENIUS, J. A. A escola da infância. São Paulo: Editora Unesp, 2011a. . Didática magna. 4. ed. São Paulo: Martins Fontes, 2011b. . Pampaedia (Educação Universal). São Paulo, SP: Editora Comenius, 2014. 
COSTA, R. A educação infantil na Idade Média. Revista Videttur, Porto: Editora Mandruvá, 2002, p. 13-20. Disponível em: < http://www. ricardocosta.com/artigo/educacao.htm>. Acesso em: 12 abr. 2018.

GASPARIN, J. L. Comênio ou da arte de ensinar tudo a todos. Campinas, SP: Papirus Editora, 1994.

HILSDORF, M. L. S. O aparecimento da escola moderna. Belo Horizonte: Autêntica, 2006.

MANACORDA, M. A. História da educaşão. São Paulo: Editora Autores Associados, 1989.

SEVERINO, A. J. Metodologia do trabalho cientifico. 23 ed. rev. e atual. São Paulo-SP: Cortez, 2007.

KULESZA, W. A. Comenius: A persistência da utopia em educação. Campinas -SP: Editora da Unicamp, 1992.

recebido em 06 out. 2017 / aprovado em 17 abr. 2018 Para referenciar este texto:

BOLLIS, R. A. A contribuição do educador Jan Amos Comenius para a primeira infância. Cadernos de Pós-graduação, São Paulo, v. 17, n.1, p. 202-220, jan./jun. 2018. Disponível em: $<$ https://doi.org/10.5585/cpg.v17n1.7970>. 